\title{
Treatment of Metastatic Castration-resistant Prostate Cancer With Abiraterone and Enzalutamide Despite PSA Progression
}

\author{
DANIEL J. BECKER ${ }^{1}$, ARJUN D. IYENGAR ${ }^{1}$, SALMAN R. PUNEKAR $^{1}$, JASON NG $^{1}$, \\ ANIKA ZAMAN $^{1}$, STACY LOEB $^{1}$, KEVIN D. BECKER $^{2}$ and DANIL MAKAROV ${ }^{1}$ \\ ${ }^{1}$ New York University School of Medicine, New York, NY, U.S.A.; \\ ${ }^{2}$ Maimonides Medical Center, Brooklyn, NY, U.S.A.
}

\begin{abstract}
Background/Aim: National guidelines offer little guidance on the use of PSA progression (PSA increase as defined below) as a clinical endpoint in metastatic castrationresistant prostate cancer ( $m C R P C)$. The aim of the study was to examine treatment patterns/outcomes with abiraterone (abi)/enzalutamide (enza) throughout PSA progression and near the end of life (EOL). Patients and Methods: Cases of $m C R P C$ treated with abi or enza from the New York Veterans Affairs (VA) from 6/2011-8/2017 were reviewed. Regression analyses were conducted to identify factors associated with continuation of abilenza treatment up to the EOL, and survival. Results: Of 184 patients, 72 received abi alone, 28 received enza alone, and 84 received both. Treatment was changed for PSA progression alone in $39.1 \%$ (abi) and $25.7 \%$ (enza) of patients. A total of 37 patients (20\%) received abilenza within 1 month before death, 30\% of whom were receiving hospice services. Older patients and black patients were less likely to receive abilenza up to the EOL. Conclusion: Abilenza are frequently discontinued for PSA progression alone and continued at EOL. The clinical benefit of these practices warrants additional study.
\end{abstract}

Disease progression in advanced prostate cancer is generally identified by an increase in prostate specific antigen (PSA), worsening symptoms, enlarged metastatic lesions, and/or development of new metastatic lesions (1). Once patients have progression of disease, there is no universal consensus guiding appropriate treatment. The Prostate Cancer Clinical Trials Working Group 3 (PCWG3) has defined PSA progression as

This article is freely accessible online.

Correspondence to: Salman R. Punekar, MD, New York University School of Medicine, 550 1st Avenue, New York 10016, NY, U.S.A Tel: +1 2125621135, e-mail: salman.punekar@nyulangone.org.

Key Words: Abiraterone, enzalutamide, prostate cancer, PSA progression. an increase in PSA greater than $25 \%$ and $>2 \mathrm{ng} / \mathrm{ml}$ above nadir, confirmed by progression at 2 timepoints at least 3 weeks apart (2). The PCWG3 has further specified, however, that PSA progression does not mandate therapy change in clinical trials. PSA progression frequently occurs during treatment, but without a clear impact on overall survival (OS); thus, continuation of therapy despite PSA increases is frequently employed (3). No data supports a clinical benefit from changing hormonal therapy based on PSA progression alone. Abiraterone (abi), an oral androgen synthesis inhibitor initially approved by the FDA in 2011, and enzalutamide (enza), an androgen receptor blocker initially approved in 2012, both improve overall survival in metastatic castrationresistant prostate cancer (CRPC) (4-9).

There are limited data describing practice patterns with abi and/or enza despite PSA increase. Continuation of androgendeprivation therapy (ADT) with gonadotropin-releasing hormone (GNRH) agonists despite PSA progression is standard prostate cancer care based on the premise that increased androgen levels would promote tumor growth at any stage of prostate cancer treatment $(10,11)$. Finally, it is unknown how many men with CRPC are continuing to receive expensive hormonal therapy up to the end of life, the benefit of such therapy immediately prior to death is also unproven.

This retrospective cohort study sought to characterize practice patterns of abiraterone and enzalutamide treatment, as well as patient outcomes in the multi-hospital Veterans Affairs (VA) healthcare system with a focus on their use despite PSA progression, and up to the end of life (EOL).

\section{Materials and Methods}

Study design. A multi-center, retrospective cohort study of patients with advanced prostate cancer at 2 participating VA medical centers (Manhattan, Brooklyn) was conducted to characterize abiraterone and enzalutamide treatment and patient outcomes. The study was approved by the institutional review board.

Population and variables. A total of 184 patients with metastatic prostate cancer who received prescriptions for abiraterone acetate or 
enzalutamide from the New York VA (VA-NYHHS) from June 2011 August 2017 were identified. Both, inpatient and outpatient medication prescribing data were reviewed. The baseline sociodemographic variables were recorded using the nationwide VA Computerized Patient Record System (CPRS). Age at time of first diagnosis was classified as follows: 41-50, 51-60; 61-70; 71-80; 81-90. Race was classified as White, Black, or Other, and Ethnicity as Hispanic or non-Hispanic. PSA values were recorde at the time of enzalutamide or abiraterone initiation, at the nadir on a given therapy, and at the time of therapy change or discontinuation. Additional clinical characteristics were collected including documented bone or visceral metastases, hospice enrollment, surgical treatment, radiation and/or chemotherapy. Based on in depth chart review, the reason for each change in therapy was further characterized. The reasons for change in therapy or discontinuation were categorized using the following code set: 1a PSA increase less than $50 \mathrm{ng} / \mathrm{ml} ; 1 \mathrm{~b}$ - PSA increase greater than 50 $\mathrm{ng} / \mathrm{ml} ; 2$ - radiographic progression (any increase in tumor burden as determined by our radiology staff) +/- PSA change; 3 - clinical progression (as determined by treating physician) +/- PSA change; 4 miscellaneous reasons (i.e. poor tolerance due to side effect profile, or other) +/- PSA change; 5 - death; 6 - denotes patients who remained on the medication at the end of the study period;

Outcome measures. The primary study outcome was duration of abi/enza treatment after PSA has reached the nadir. For calculations of time from nadir to peak, 11 patients who had no interval values between nadir and peak were excluded, ensuring that treating physicians intentionally treated while the PSA was rising. Secondary outcomes of interest included abi/enza continuation despite radiographic and clinical progression, use of abi/enza within the last month of life, and reasons for medication change. Additional secondary outcomes included PSA nadir and peak on abi/enza therapy, and survival from initiation of abi/enza therapy.

Statistics. Descriptive statistics were applied and univariate and multivariable logistic regression was used to explore associations between clinical/demographic variables (age, race, presence of bone metastases, ethnicity) and continuation of abi/enza despite PSA progression Cox $\mathrm{PH}$ models were used to examine associations between clinical/demographic factors and overall survival. All statistical analyses were conducted using SAS 9.2 software, with $p<0.05$ used as the level of statistical significance.

\section{Results}

Baseline clinical characteristics of study participants are listed in Table I. This study identified 184 patients diagnosed with metastatic CRPC who had received abi/enza from June 2011 August 2017. Eleven (6\%) patients were excluded from calculations of time of treatment despite PSA progression because they had no rising value above the nadir. Of the study population, $46 \%$ were white, $44 \%$ were black, and $10 \%$ were another race; along ethnic lines, $6.5 \%$ were Hispanic and $93.5 \%$ were non-Hispanic. The median age of cases was 68 (with ages ranging from 43-90), with $49.5 \%$ of patients alive and $50.5 \%$ of patients deceased by the time of study analysis. $24 \%$ of patients had received surgery, $25.5 \%$ chemotherapy, and $57 \%$ radiation. Seventy-eight percent had bone metastases.
Of 184 patients, 72 patients received abi alone, 28 received enza alone, and 84 received both (i.e., 156 patients received abi and 112 received enza overall). Median starting PSA on abi was $26.7 \mathrm{ng} / \mathrm{ml}$, median PSA decrease on abi was $22.47 \mathrm{ng} / \mathrm{ml}$ and median increase from nadir was $23.78 \mathrm{ng} / \mathrm{ml}$. Median continuation of therapy beyond PSA nadir was 7 months. The median time to nadir was 5 months. These data are illustrated in Figure 1. Of patients who were treated with abiraterone, $78 \%$ were continued through PSA increase. Comparatively, median starting PSA for enzalutamide was $33.5 \mathrm{ng} / \mathrm{ml}$, median PSA decrease on enza was $21.58 \mathrm{ng} / \mathrm{ml}$ and median increase from nadir was $37.8 \mathrm{ng} / \mathrm{ml}$. Median continuation of therapy beyond PSA nadir was 4.5 months and median treatment time prior to nadir was 2 months. Overall, 64\% of patients continued enza through PSA increase.

Biochemical progression alone was the rationale for treatment cessation in $39.1 \%$ and $25.7 \%$ of patients receiving abi and enza, respectively, while the remaining of treatment changes involved combined biochemical, radiographic and clinical changes, as shown in Figure 2. Among the 61 patients whose abi was stopped because of PSA progression only, the median duration of abi treatment was 364 days vs 216 days among those whose abi was stopped for other reasons $(p=0.03$; Wilcoxon-Mann-Whitney test). No clinical or demographic characteristics predicted PSA related stoppage of abiraterone. In multivariable logistic regression (Table II), when adjusted for age, race, and presence of bone metastases, older patients $(\mathrm{OR}=0.57,95 \% \mathrm{CI}=0.36-0.91)$ and black patients $(\mathrm{OR}=0.41$, $95 \% \mathrm{CI}=0.18-0.93)$ were less likely to receive a prescription within 1 month prior to death. In a Cox PH model, black race $(\mathrm{HR}=2.21,95 \% \mathrm{CI}=1.28-3.82)$ and receipt of medication within 1 month prior to death $(\mathrm{HR}=9.39,95 \% \mathrm{CI}=5.29-16.66)$ were associated with worse overall survival from abi/enza initiation. Continuation of abi despite PSA change by $>50 \mathrm{ng} / \mathrm{ml}$ was not associated with improved overall survival. Of 37 (20.1\%) patients who received abi/enza within 1-month prior death, $30 \%$ received continued treatment while receiving hospice services.

\section{Discussion}

PSA increase provides initial evidence that neoplastic resistance to the medication is increasing, and frequently precedes clinical progression. PSA increase has not, however, been shown to be a clinically meaningful endpoint for changes in therapy. Based on the observation that prostate cancer maintains testosterone responsiveness after PSA progression, continuation of hormonal therapy despite increase in PSA is common. Real-world practice outside of clinical trials after PSA increase is unknown.

Our study revealed that in our VA population, more patients were treated with abiraterone than enzalutamide, likely in part because abiraterone was approved first (April 2011 vs. August 2012). Both drugs were available at the VA 
Table I. Demographics table (Raw Data). Characteristics of subjects with castrate resistant prostate cancer treated with abiraterone, enzalutamide, or both.

\begin{tabular}{|c|c|c|c|c|}
\hline & $\begin{array}{l}\text { All Patients } \\
\quad \mathrm{N}=184\end{array}$ & $\begin{array}{l}\text { Abiraterone } \\
\quad 72\end{array}$ & $\begin{array}{l}\text { Enzalutamide } \\
28\end{array}$ & $\begin{array}{l}\text { Abiraterone and Enzalutamide } \\
\qquad 84\end{array}$ \\
\hline Age Dx, mean (yrs) & 68.7458 & 66.157 & 63.7 & 66.976 \\
\hline $41-50$ & $1(0.5)$ & 0 & 0 & $1(1.2)$ \\
\hline $51-60(\%)$ & $30(16.3)$ & $11(15.7)$ & $4(13.33)$ & $15(17.85)$ \\
\hline $61-70$ & $78(42.4)$ & $27(38.6)$ & $14(46.67)$ & $37(44.0)$ \\
\hline $71-80$ & $48(26.1)$ & $18(25.7)$ & $7(23.33)$ & $23(27.4)$ \\
\hline $81-90$ & $20(10.9)$ & $10(14.28)$ & $3(10.0)$ & $7(8.04)$ \\
\hline Unknown & $7(4.35)$ & $4(5.71)$ & $2(6.67)$ & $1(1.2)$ \\
\hline \multicolumn{5}{|l|}{ Treatment Received: } \\
\hline Surgical intervention (\%) & $24.46(45 / 184)$ & $18.57(13 / 70)$ & $13.33(4 / 30)$ & $33.33(28 / 84)$ \\
\hline Radiation therapy $(\%)$ & $58.15(107 / 184)$ & $51.42(36 / 70)$ & $46.67(14 / 30)$ & $67.86(57 / 84)$ \\
\hline Chemotherapy $(\%)$ & $25.54(47 / 184)$ & $15.71(11 / 70)$ & $20.0(6 / 30)$ & $35.71(30 / 84)$ \\
\hline Percentage with bone metastases (\%) & $77.77(143 / 184)$ & $81.43(57 / 70)$ & $53.33(16 / 30)$ & $83.33(70 / 84)$ \\
\hline \multicolumn{5}{|l|}{ Race, No. $(\%)$} \\
\hline Black & $81(44.0)$ & $32(55.7)$ & $11(36.67)$ & $38(45.2)$ \\
\hline White & $84(45.65)$ & $31(44.3)$ & $15(50)$ & $38(45.2)$ \\
\hline Other & $19(10.33)$ & $7(10)$ & $4(13.33)$ & $8(9.52)$ \\
\hline \multicolumn{5}{|l|}{ Ethnicity } \\
\hline Hispanic & $12(6.52)$ & $3(4.3)$ & $2(6.67)$ & $7(8.33)$ \\
\hline Non-Hispanic & $172(93.47)$ & $67(95.7)$ & $28(93.33)$ & $77(91.67)$ \\
\hline Median survival lived past initial diagnosis (mo.) & 120 & 107 & 120 & 144 \\
\hline Median survival lived past abi/enza initiation (mo.) & 21 & 13 & 14 & 28 \\
\hline \multicolumn{5}{|l|}{ Date of first treatment with abi/enza } \\
\hline Unknown & & 1 & 0 & 0 \\
\hline 2011 & & 5 & 0 & Abi 4; Enza 0 \\
\hline 2012 & & 18 & 0 & Abi 10 ; Enza 3 \\
\hline 2013 & & 18 & 2 & Abi 29; Enza 13 \\
\hline 2014 & & 10 & 3 & Abi 15; Enza 20 \\
\hline 2015 & & 9 & 5 & Abi 13; Enza 17 \\
\hline 2016 & & 6 & 10 & Abi 9; Enza 15 \\
\hline 2017 & & 5 & 8 & Abi 4 ; Enza 16 \\
\hline \multicolumn{5}{|l|}{ Living/Deceased, No. (\%) } \\
\hline $\begin{array}{l}\text { Living } \\
\text {. }\end{array}$ & $91(49.46)$ & $27(38.57)$ & $21(70.0)$ & $43(51.19)$ \\
\hline Deceased & $93(50.54)$ & $43(61.43)$ & $9(30.0)$ & $41(48.81)$ \\
\hline
\end{tabular}

For some patients the age at first diagnosis is missing.

within 6 months of approval. Additionally, patients were treated with abiraterone, on average, for more than twice the period patients were treated with enzalutamide, also likely related to the fact that it was more often used first. Remarkably, PSA levels at time of abi initiation and time of abi discontinuation were similar and PSA nadir was located approximately in the middle of these time points. The median PSA values illustrated in Figure 1, suggest that treatment despite PSA increase yields a clinically significant period without clinical or radiographic progression. Enzalutamide was started at higher PSA levels in general, continued through nadir and then frequently to PSA levels higher than those at enzalutamide initiation. Again, enzalutamide continuation despite PSA nadir was associated with a clinically meaningful interval without radiographic or clinical progression. Our study is consistent with a recently published study, which suggested an OS benefit for patients treated with abiraterone and prednisone despite PSA and radiographic progression, relative to patients whose therapy was stopped pending for radiographic and/or PSA progression (12).

As illustrated in Figure 3, patients who received both (sequentially, not concurrently) abiraterone and enzalutamide lived longer than those who received only abiraterone (median values 36 months compared to 20 months, median for patients treated with enzalutamide was not yet reached). These differences are likely due to selection of stable patients with limited comorbidities for second- and third-line therapies. Nonetheless, the survival in our VA population is comparable to that seen in clinical trials $(4,7)$ supporting the real-world efficacy of these medications. 


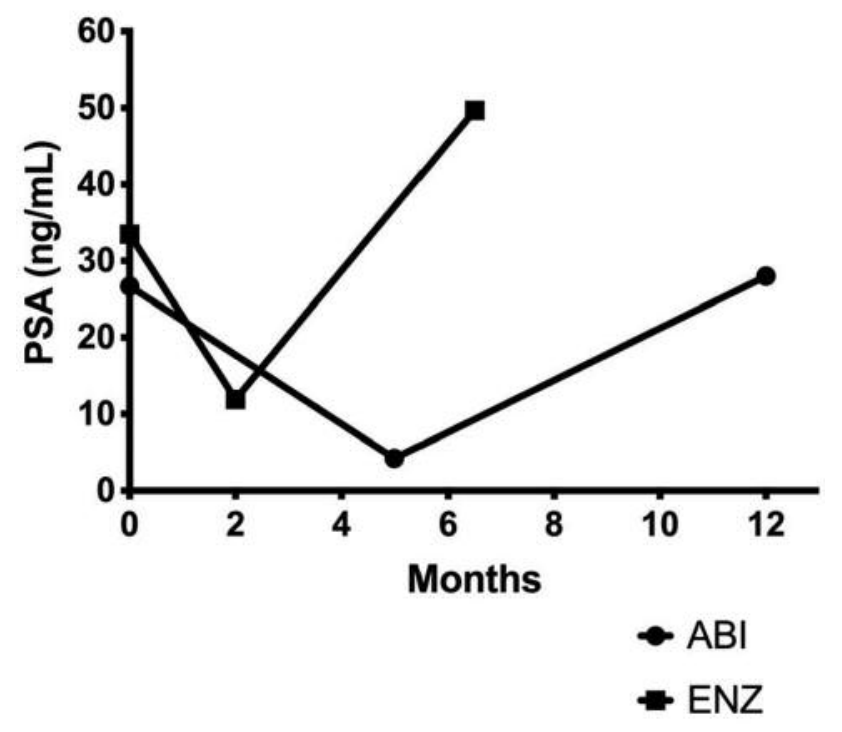

Figure 1. Median PSA values $(\mathrm{ng} / \mathrm{ml})$ at initiation of treatment, at nadir, and at time of treatment discontinuation. Time to nadir and peaks are shown as median values.
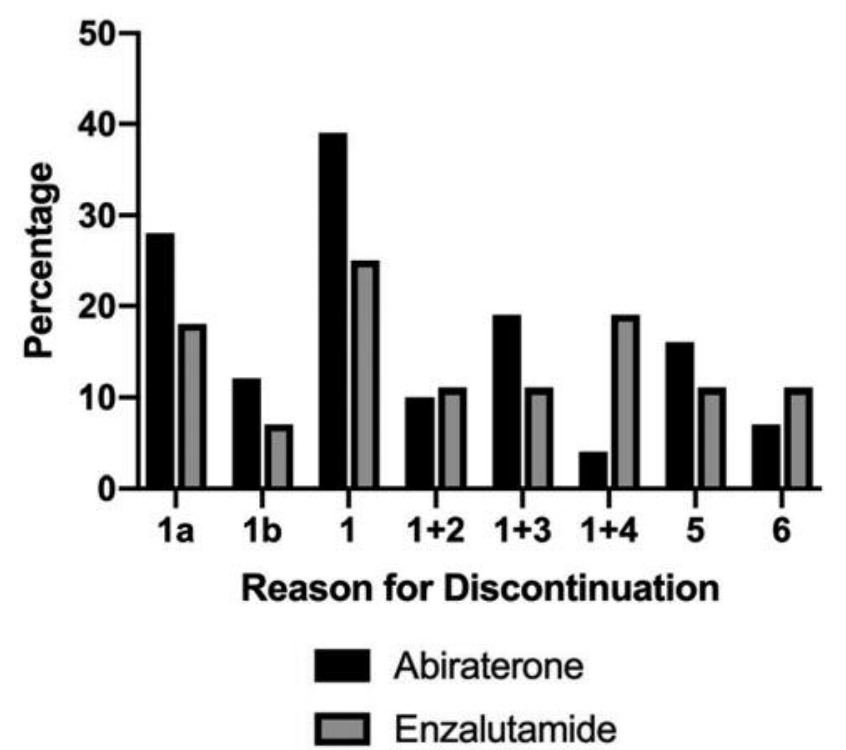

Figure 2. Reasons for discontinuation of abiraterone and enzalutamide. 1a: PSA increase less than $50 \mathrm{ng} / \mathrm{ml}$. $1 \mathrm{~b}$ : PSA increase greater than $50 \mathrm{ng} / \mathrm{ml}$ 1: PSA change only. 1+2: PSA change and/or radiographic progression. 1+3: PSA change and/or clinical progression. 1+4: PSA change and/or Misc. 5: Death. 6: Patient remained on medication.

Reasons for change in therapy were PSA progression, radiographic progression, clinical progression, death, poor tolerance of medication, or a combination of these. The most common reason for discontinuation or change of therapy was

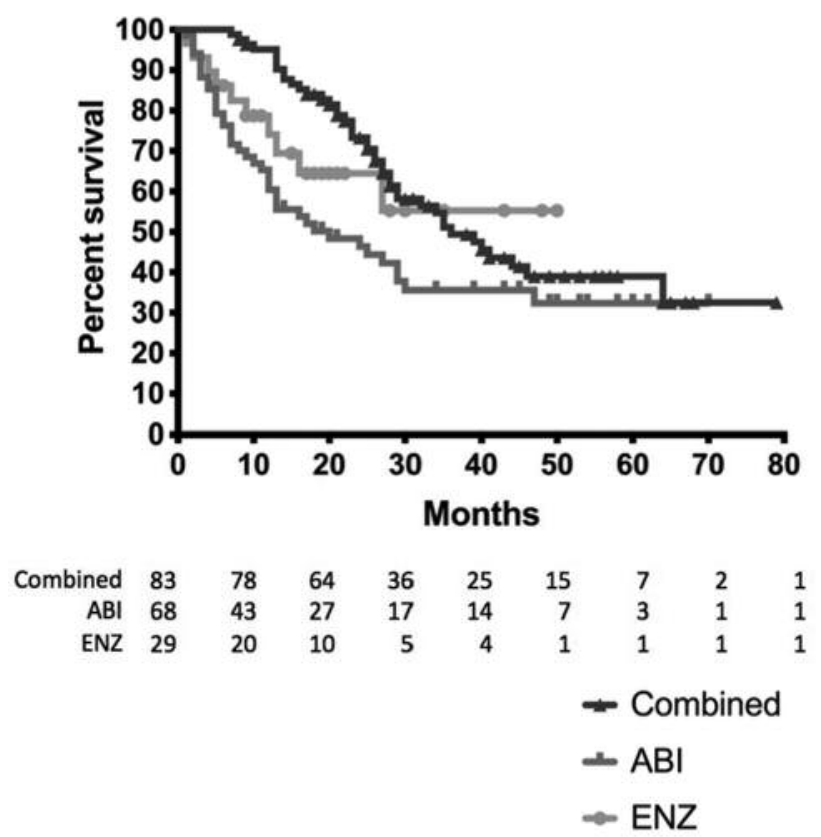

Figure 3. Kaplan-Meier survival curve showing overall survival of patients treated with abiraterone, enzalutamide, or a combination of both. The table below the survival curve depicts the number at risk at each 10-month interval.

Table II. Multivariable logistic regression for receipt of treatment within 30 days prior to death.

\begin{tabular}{lccc}
\hline Variable & OR & $95 \% \mathrm{CI}$ & $p$-Value \\
\hline Age & 0.57 & $0.36-0.91$ & 0.02 \\
Race: black $v s$. white & 0.41 & $0.18-0.93$ & 0.63 \\
Race: other $v s$. white & 0.28 & $0.06-1.40$ & 0.30 \\
Ethnicity: Hispanic $v s$. Not Hispanic & 0.26 & $0.03-2.21$ & 0.22 \\
Presence of bone metastasis & 0.45 & $0.14-1.42$ & 0.17 \\
\hline
\end{tabular}

PSA progression alone (Figure 2). It is interesting to note that despite the common practice of continuation despite PSA progression, PSA progression remains a major reason for change in therapy. Neither the NCCN nor the ASCO guidelines advise that PSA increases warrant changes in therapy $(13,14)$. In our patient population there appears to be a point at which the treating physician and/or patient will no longer tolerate additional PSA increase. It is noteworthy that patients whose abiraterone was discontinued based on PSA change alone, had a longer duration of abiraterone therapy, medians 394 vs. 219 days. It is not clear that this decision is evidence-based. The median increase in PSA among patients for whom PSA increase alone was the reason for change in therapy was $23.7 \mathrm{ng} / \mathrm{ml}$ and $34.9 \mathrm{ng} / \mathrm{ml}$ for those on abiraterone and enzalutamide, 
respectively. The median increase in PSA among patients for whom radiographic, clinical or other reasons warranted therapy change was $19.2 \mathrm{ng} / \mathrm{ml}$ and $10.7 \mathrm{ng} / \mathrm{ml}$ for those on abiraterone and enzalutamide, respectively. Enza discontinuation for PSA progression only was less common than for abi $(25.7 \%$ compared to $39.1 \%$ ). This is likely influenced by the frequent use of enza after failure of abi, thus leaving clinicians and patients with limited additional options, and higher tolerance for PSA increase. Interestingly, radiographic progression was almost always accompanied by PSA progression.

Approximately $20 \%$ of patients were continued on either abiraterone or enzalutamide within one month prior to death. Of these, $30 \%$ received it while they were in hospice care In 2012, the American Society of Clinical Oncologists (ASCO) issued recommendations as part of their "Choosing Wisely" campaign to minimize the use of unnecessary antineoplastic therapy at the end of life (15-18). The monthly cost (wholesale acquisition cost) of abiraterone is approximately $\$ 8,000$ and the monthly cost of enzalutamide is approximately $\$ 9,000$ (19). Continuation at the end of life consumes resources and should only be considered in the setting of compelling evidence that the drugs are providing symptomatic benefit. In our study alone, this accounted for a cost of approximately $\$ 315,000$ for 37 patients receiving therapy in the last month of life. Of note, Black patients in our study were less likely than white patients to be treated with abi/enza in the last month of life. In this regard Black patients may have received more evidence-based end of life care, but any differences by race warrant further evaluation. The reasons for this racial association remain unknown. Black patients also had worse survival from the time of abi/enza initiation. Previous studies have established differences in outcomes for Black patients with prostate cancer, likely related to differences in pathology, treatment, and social factors (20-29). We were not able to fully account for these additional variables in our models.

Our study has several significant limitations. A relatively small number of patients were analyzed, and they were treated by a small group of physicians. Patterns may not be representative of larger physician and/or patient samples. PSA levels were not measured at prespecified standard timepoints for all patients, which allowed us to only effectively comment on the peaks and nadirs of PSA for this group of patients. For similar reasons we were unable to calculate the rate of PSA change. There was no uniform standard for PSA- only progression, (as the $25 \%$ increase in nadir used in studies), but this may be representative of community care. All-cause mortality was used as our primary survival outcome, and it is possible that non-cancer related deaths contributed.

Nonetheless, the value of the study is that it adds to the remarkably scarce literature on practice patterns after PSA increase, and reasons for therapy change. Physicians are frequently confronted with this situation and lack guideline recommendations to help them to get informed decisions. Our study suggests that there is significant value to extending abi and/or enza treatment past PSA nadir in patients who are otherwise responding. The data also suggests that there comes a point beyond which treating physicians may change therapy based on additional PSA increase, despite other clinical factors reflecting stable disease. More studies are urgently needed for informed clinical decisions in CRPC patients with substantial increases in PSA during abi and enza, and to ensure evidence-based decisions about continued use of costly medications during the end of life care.

\section{Conflicts of Interest}

The Authors declare no conflicts of interest relevant to this article.

\section{Authors' Contributions}

Conception and design: Daniel J. Becker, Arjun D. Iyengar; Collection and assembly of data: Daniel J. Becker, Arjun D. Iyengar, Jason Ng, Anika Zaman, Salman R. Punekar; Data analysis and interpretation: Daniel J. Becker, Arjun D. Iyengar, Salman R. Punekar, Kevin D. Becker, Danil Makarov, Stacey Loeb; Manuscript writing: Daniel J. Becker, Salman R. Punekar, Stacey Loeb, Jason $\mathrm{Ng}$, Arjun D. Iyengar, Kevin D. Becker, Danil Makarov; Final approval of manuscript: All Authors.

\section{Acknowledgements}

Funding: This research did not receive any specific grant from funding agencies in the public, commercial, or not-for-profit sectors.

\section{References}

1 Scher HI, Morris MJ, Basch E and Heller G: End points and outcomes in castration-resistant prostate cancer: From clinical trials to clinical practice. J Clin Oncol 29: 3695-3704, 2011. PMID: 21859988. DOI: 10.1200/JCO.2011.35.8648

2 Scher HI, Morris MJ, Stadler WM, Higano C, Basch E, Fizazi $\mathrm{K}$, Antonarakis ES, Beer TM, Carducci MA, Chi KN, Corn PG, de Bono JS, Dreicer R, George DJ, Heath EI, Hussain M, Kelly WK, Liu G, Logothetis C, Nanus D, Stein MN, Rathkopf DE, Slovin SF, Ryan CJ, Sartor O, Small EJ, Smith MR, Sternberg CN, Taplin ME, Wilding G, Nelson PS, Schwartz LH, Halabi S, Kantoff PW, Armstrong AJ and Prostate Cancer Clinical Trials Working Group 3: Trial design and objectives for castrationresistant prostate cancer: updated recommendations from the prostate cancer clinical trials working group 3. J Clin Oncol 34: 1402-1418, 2016. PMID: 26903579. DOI: 10.1200/JCO.2015. 64.2702

3 Conteduca V, Caffo O, Lolli C, Aieta M, Scarpi E, Bianchi E, Maines F, Schepisi G, Salvi S, Massari F, Carrozza F, Veccia A, Chiuri VE, Campadelli E, Facchini G and De Giorgi U: Longterm clinical impact of PSA surge in castration-resistant prostate cancer patients treated with abiraterone. Prostate 77: 1012-1019, 2017. PMID: 28429372. DOI: $10.1002 /$ pros. 23357 
4 de Bono JS, Logothetis CJ, Molina A, Fizazi K, North S, Chu L, Chi KN, Jones RJ, Goodman OB, Saad F, Staffurth JN, Mainwaring P, Harland S, Flaig TW, Hutson TE, Cheng T, Patterson H, Hainsworth JD, Ryan CJ, Sternberg CN, Ellard SL, Fléchon A, Saleh M, Scholz M, Efstathiou E, Zivi A, Bianchini D, Loriot Y, Chieffo N, Kheoh T, Haqq CM, Scher HI and COUAA-301 Investigators: Abiraterone and increased survival in metastatic prostate cancer. N Engl J Med 364: 1995-2005, 2011. PMID: 21612468. DOI: 10.1056/NEJMoa1014618

5 Ryan CJ, Smith MR, Fizazi K, Saad F, Mulders PFA, Sternberg CN, Miller K, Logothetis CJ, Shore ND, Small EJ, Carles J, Flaig TW, Taplin M-E, Higano CS, de Souza P, de Bono JS, Griffin TW, De Porre P, Yu MK, Park YC, Li J, Kheoh T, Naini V, Molina A, Rathkopf DE and COU-AA-302 Investigators: Abiraterone acetate plus prednisone versus placebo plus prednisone in chemotherapy-naive men with metastatic castration-resistant prostate cancer (COU-AA-302): final overall survival analysis of a randomised, double-blind, placebocontrolled phase 3 study. Lancet Oncol 16: 152-160, 2015. PMID: 25601341. DOI: 10.1016/S1470-2045(14)71205-7

6 Ryan CJ, Smith MR, de Bono JS, Molina A, Logothetis CJ, de Souza P, Fizazi K, Mainwaring P, Piulats JM, Ng S, Carles J, Mulders PFA, Basch E, Small EJ, Saad F, Schrijvers D, Van Poppel H, Mukherjee SD, Suttmann H, Gerritsen WR, Flaig TW, George DJ, Yu EY, Efstathiou E, Pantuck A, Winquist E, Higano CS, Taplin M-E, Park Y, Kheoh T, Griffin T, Scher HI and Rathkopf DE: Abiraterone in metastatic prostate cancer without previous chemotherapy. N Engl J Med 368: 138-148, 2013. PMID: 23228172. DOI: 10.1056/NEJMoa1209096

7 Beer TM, Armstrong AJ, Rathkopf DE, Loriot Y, Sternberg CN, Higano CS, Iversen P, Bhattacharya S, Carles J, Chowdhury S, Davis ID, de Bono JS, Evans CP, Fizazi K, Joshua AM, Kim CS, Kimura G, Mainwaring P, Mansbach H, Miller K, Noonberg SB, Perabo F, Phung D, Saad F, Scher HI, Taplin M-E, Venner PM, Tombal B and PREVAIL Investigators: Enzalutamide in metastatic prostate cancer before chemotherapy. N Engl J Med 371: 424-433, 2014. PMID: 24881730. DOI: 10.1056/ NEJMoa1405095

8 Hussain M, Fizazi K, Saad F, Rathenborg P, Shore N, Ferreira U, Ivashchenko P, Demirhan E, Modelska K, Phung D, Krivoshik A and Sternberg $\mathrm{CN}$ : Enzalutamide in men with nonmetastatic, castration-resistant prostate cancer. N Engl J Med 378: 2465-2474, 2018. PMID: 29949494. DOI: 10.1056/ NEJMoa1800536

9 Scher HI, Fizazi K, Saad F, Taplin M-E, Sternberg CN, Miller K, de Wit R, Mulders P, Chi KN, Shore ND, Armstrong AJ, Flaig TW, Fléchon A, Mainwaring P, Fleming M, Hainsworth JD, Hirmand M, Selby B, Seely L, de Bono JS and AFFIRM Investigators: Increased survival with enzalutamide in prostate cancer after chemotherapy. N Engl J Med 367: 1187-1197, 2012. PMID: 22894553. DOI: 10.1056/NEJMoa1207506

10 Taylor CD, Elson P and Trump DL: Importance of continued testicular suppression in hormone-refractory prostate cancer. J Clin Oncol 11: 2167-2172, 1993. PMID: 8229130. DOI: 10.1200/JCO.1993.11.11.2167

11 Hussain M, Wolf M, Marshall E, Crawford ED and Eisenberger M: Effects of continued androgen-deprivation therapy and other prognostic factors on response and survival in phase II chemotherapy trials for hormone-refractory prostate cancer: a Southwest Oncology Group report. J Clin Oncol 12: 1868-1875, 1994. PMID: 8083710. DOI: 10.1200/JCO.1994.12.9.1868
12 Biró K, Budai B, Szőnyi M, Küronya Z, Gyergyay F, Nagyiványi $\mathrm{K}$ and Géczi L: Abiraterone acetate + prednisolone treatment beyond prostate specific antigen and radiographic progression in metastatic castration-resistant prostate cancer patients. Urol Oncol Semin Orig Investig 36: 81.e1-81.e7, 2018. PMID: 29153623. DOI: 10.1016/j.urolonc.2017.10.015

13 NCCN Clinical Practice Guidelines in Oncology (NCCN Guidelines ${ }^{\circledR}$ ) Prostate Cancer, 2018.

14 Virgo KS, Basch E, Loblaw DA, Oliver TK, Rumble RB, Carducci MA, Nordquist L, Taplin ME, Winquist E and Singer EA: Second-line hormonal therapy for men with chemotherapynaïve, castration-resistant prostate cancer: American Society of Clinical Oncology Provisional Clinical Opinion. J Clin Oncol 35: 1952-1964, 2017. PMID: 28441112. DOI: 10.1200/ JCO. 2017.72.8030

15 LeBlanc TW, McNeil MJ, Kamal AH, Currow DC and Abernethy AP: Polypharmacy in patients with advanced cancer and the role of medication discontinuation. Lancet Oncol 16: e333-e341, 2015. PMID: 26149885. DOI: 10.1016/S14702045(15)00080-7

16 Newport K, Holliday R, McNaughton C, Gehron E, Horst M and Sivendran S: A description of cancer directed therapy within 14 days of death in a community cancer institute. J Clin Oncol 35: 73-73, 2017.

17 American Society of Clinical Oncology- Choosing Wisely: Ten Things Physicians and Patients Should Question. Available from: http://www.choosingwisely.org/societies/american-society-ofclinical-oncology/ [last accessed April 10, 2019].

18 Chen RC, Falchook AD, Tian F, Basak R, Hanson L, Selvam N and Dusetzina S: Aggressive care at the end-of-life for younger patients with cancer: Impact of ASCO's Choosing Wisely campaign. J Clin Oncol 34: LBA10033-LBA10033, 2016.

19 Pilon D, Queener M, Lefebvre P and Ellis LA: Cost per median overall survival month associated with abiraterone acetate and enzalutamide for treatment of patients with metastatic castrationresistant prostate cancer. J Med Econ 19: 777-784, 2016. PMID: 27031255. DOI: 10.3111/13696998.2016.1173042

20 Hankey BF, Feuer EJ, Clegg LX, Hayes RB, Legler JM, Prorok PC, Ries LA, Merrill RM and Kaplan RS: Cancer surveillance series: interpreting trends in prostate cancer--part I: Evidence of the effects of screening in recent prostate cancer incidence, mortality, and survival rates. J Natl Cancer Inst 91: 1017-1024, 1999. PMID: 10379964.

21 Baquet CR, Horm JW, Gibbs T and Greenwald P: Socioeconomic factors and cancer incidence among blacks and whites. J Natl Cancer Inst 83: 551-557, 1991. PMID: 2005640.

22 Ingles SA, Coetzee GA, Ross RK, Henderson BE, Kolonel LN, Crocitto L, Wang W and Haile RW: Association of prostate cancer with vitamin D receptor haplotypes in AfricanAmericans. Cancer Res 58: 1620-1623, 1998. PMID: 19961572. DOI: $10.1186 / 1471-2350-10-125$

23 Parker PM, Rice KR, Sterbis JR, Chen Y, Cullen J, McLeod DG and Brassell SA: Prostate cancer in men less than the age of 50: a comparison of race and outcomes. Urology 78: 110-115, 2011. PMID: 21397300. DOI: 10.1016/j.urology.2010.12.046

24 Hoffman RM, Gilliland FD, Eley JW, Harlan LC, Stephenson RA, Stanford JL, Albertson PC, Hamilton AS, Hunt WC and Potosky AL: Racial and ethnic differences in advanced-stage prostate cancer: the Prostate Cancer Outcomes Study. J Natl Cancer Inst 93: 388-395, 2001. PMID: 11238701. 
25 Powell IJ, Banerjee M, Sakr W, Grignon D, Wood DP, Novallo $\mathrm{M}$ and Pontes E: Should African-American men be tested for prostate carcinoma at an earlier age than white men? Cancer 85: 472-477, 1999. PMID: 28830287. DOI: $10.1177 / 15579883$ 17721107

26 Cross CK, Shultz D, Malkowicz SB, Huang WC, Whittington R, Tomaszewski JE, Renshaw AA, Richie JP and D'Amico A V: Impact of race on prostate-specific antigen outcome after radical prostatectomy for clinically localized adenocarcinoma of the prostate. J Clin Oncol 20: 2863-2868, 2002. PMID: 12065563. DOI: $10.1200 / \mathrm{JCO} .2002 .11 .054$

27 Harlan LC, Potosky A, Gilliland FD, Hoffman R, Albertsen PC, Hamilton AS, Eley JW, Stanford JL and Stephenson RA: Factors associated with initial therapy for clinically localized prostate cancer: prostate cancer outcomes study. J Natl Cancer Inst 93: 1864-1871, 2001. PMID: 11752011.
28 Bennett CL, Ferreira MR, Davis TC, Kaplan J, Weinberger M, Kuzel T, Seday MA and Sartor O: Relation between literacy, race, and stage of presentation among low-income patients with prostate cancer. J Clin Oncol 16: 3101-3104, 1998. PMID: 9738581. DOI: 10.1200/JCO.1998.16.9.3101

29 Krupski TL, Kwan L, Afifi AA and Litwin MS: Geographic and socioeconomic variation in the treatment of prostate cancer. J Clin Oncol 23: 7881-7888, 2005. PMID: 16204005. DOI: 10.1200/JCO.2005.08.755

Received February 28, 2019

Revised April 11, 2019

Accepted April 15, 2019 